\title{
A Mutation in the Surfactant Protein B Gene Responsible for Fatal Neonatal Respiratory Disease in Multiple Kindreds
}

\author{
Lawrence M. Nogee, * Gerard Garnier, ${ }^{\star}$ Harry C. Dietz, * Lori Singer, ${ }^{\star}$ Anne M. Murphy, * Daphne E. deMello," \\ and Harvey R. Colten* \\ ${ }^{*}$ Department of Pediatrics, Johns Hopkins University School of Medicine, Baltimore, Maryland 21287; ${ }^{\ddagger}$ Department of Pediatrics, \\ Washington University School of Medicine, St. Louis, Missouri 63110; and $\$$ Department of Pathology, \\ St. Louis University School of Medicine, St. Louis, Missouri 63117
}

\begin{abstract}
To determine the molecular defect accounting for the deficiency of pulmonary surfactant protein B (SP-B) in full-term neonates who died from respiratory failure associated with alveolar proteinosis, the sequence of the SP-B transcript in affected infants was ascertained. A frameshift mutation consisting of a substitution of GAA for $\mathrm{C}$ in codon 121 of the SP-B cDNA was identified. The three affected infants in the index family were homozygous for this mutation, which segregated in a fashion consistent with autosomal recessive inheritance of disease. The same mutation was found in two other unrelated infants who died from alveolar proteinosis, one of whom was also homozygous, and in the parents of an additional unrelated, affected infant, but was not observed in $\mathbf{5 0}$ control subjects. We conclude that this mutation is responsible for SP-B deficiency and neonatal alveolar proteinosis in multiple families and speculate that the disorder is more common than was recognized previously. ( $J$. Clin. Invest. 1994. 93:1860-1863.) Key words: newborn • respiratory distress syndrome - pulmonary alveolar proteinosis • bronchopulmonary dysplasia $\bullet$ lung diseases
\end{abstract}

\section{Introduction}

A developmentally determined lack of pulmonary surfactant, the mixture of lipids and specific proteins that reduces alveolar surface tension, is recognized as the principal cause of the respiratory distress syndrome in infants born prematurely (1). A deficiency of surfactant protein B (SP-B), ${ }^{1}$ an 8,000-D lungspecific protein, was recently demonstrated in three full-term siblings who died from respiratory failure associated with histopathologic changes of alveolar proteinosis (2). SP-B has an important role in the surface tension-lowering properties of pulmonary surfactant, and congenital alveolar proteinosis

Address correspondence to Dr. Lawrence M. Nogee, Division of Neonatology, CMSC 210, The Johns Hopkins Children's Center, 600 North Wolfe Street, Baltimore, MD 21287-3200.

Received for publication 18 October 1993 and in revised form 6 December 1993.

1. Abbreviations used in this paper: $\mathrm{CAP}$, congenital alveolar proteinosis; RT, reverse transcription; SP, surfactant protein.

J. Clin. Invest.

(C) The American Society for Clinical Investigation, Inc.

0021-9738/94/04/1860/04 \$2.00

Volume 93, April 1994, 1860-1863
(CAP) is a recognized familial cause of fatal respiratory disease in full-term infants (3-6). These observations suggest that an inherited deficiency of SP-B may cause this disorder and that abnormalities of surfactant proteins due to genetic mechanisms could cause respiratory disease. To test these hypotheses and to elucidate the molecular mechanisms responsible for the lack of SP-B in these infants, we analyzed the SP-B transcripts in infants with CAP from unrelated families and compared them with previously published SP-B cDNA and genomic sequences $(7-10)$.

\section{Methods}

Patients. The clinical course of infants from the index family (patients II.1, II.5, and II.6) and patient CAP-2 has been described previously (2, 6). Patient CAP-3 was a 3-kg Caucasian female who developed respiratory distress shortly after birth and who subsequently required intubation, mechanical ventilation, and extracorporeal membrane oxygenation. Open lung biopsy at 2 mo of age demonstrated characteristic findings of alveolar proteinosis: distal airspaces were filled with granular, eosinophilic material that stained positively with periodic acidSchiff reagent, with foamy macrophages suspended in the proteinaceous material. She died at age $3 \mathrm{mo}$ from respiratory failure; findings of alveolar proteinosis were also present at autopsy. Lung tissue from patients CAP-2 and CAP-3 was analyzed for SP-B content by immunohistochemical staining and protein blotting as described previously (2). Control blood samples were obtained from healthy adult volunteers without symptoms of pulmonary disease.

cDNA preparation and sequencing. Total cellular RNA was prepared from lung tissue frozen at the time of biopsy (patient II.5) or rapid autopsy (patient II.6) by an acid phenol extraction method (11). Overlapping cDNA clones (spanning nucleotides 15-650, 22-761, 682-1405, and 1172-1947) were generated by reverse transcription (RT) of $5 \mu \mathrm{g}$ of total cellular RNA using SP-B-specific antisense primers, followed by PCR amplification, and subcloning the products into a plasmid vector ( $\mathrm{TA}^{\mathrm{R}}$ cloning vector; Invitrogen, San Diego, $\mathrm{CA}$ ) according to the methods suggested by the manufacturer. For the most 5 ' and 3' sequences, genomic DNA sequences from nucleotides -108 to 395 and 9052 to 9399 were amplified by PCR from patient II.6 and subcloned. For the cDNA clone whose partial sequence is shown in Fig. 1, the antisense SP-B-specific primer used was 5'-AGA GCC CTG CAG AGC CAG CAA TAG GGG AGA-3', and the sense primer used was 5'-ATG GCT GAG TCA CAC CTG CTG CAG TGG CTG-3'. 5 $\mu \mathrm{g}$ of plasmid DNA containing the cDNA insert was denatured and sequenced by the dideoxy chain termination method (12) (Sequenase, V2.0; United States Biochemical Corp., Cleveland, $\mathrm{OH}$ ) with incorporation of ${ }^{35} \mathrm{~S}$-dATP. The sequencing primer used was 5'-TTC CTG GAG CAG GAG TGC-3'. The products were separated on a $6 \%$ denaturing polyacrylamide gel and visualized by autoradiography. Sequence analysis was repeated on two separately generated PCR products from each of two affected siblings (patients II.5 and II.6). 


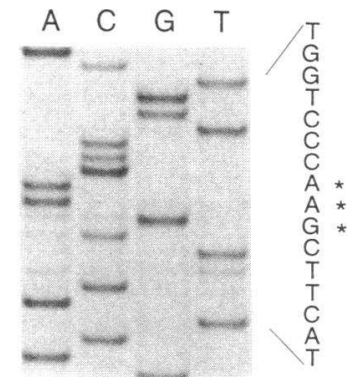

$\begin{array}{lllll}119 & 120 & 121 & 122 & 123\end{array}$

Tyr Phe Pro Leu Val

NORMAL: TAC TTC OCC CTG GTC

SP-B DEFICIENT: TAC TTC GAA CCC TGG

Tyr Phe Asp Pro Trp
Figure 1. DNA sequence demonstrating 121 ins 2 mutation. The DNA sequence ladder of the sense strand of a cDNA clone from the index infant with SP-B deficiency (patient II.5) in the region of the mutation is shown. The normal SP-B cDNA sequence is listed below for comparison. In codon 121 there is a 3-bp substitution of GAA for $\mathrm{C}$, marked with asterisks.

Genomic DNA preparation and restriction analysis. Genomic DNA was prepared from whole blood lymphocytes (patients I.1, I.2, II.2, II.3, II.4, and controls), frozen lung tissue (patients II.5, II.6, CAP-2, and CAP-3), or formalin-fixed paraffin-embedded lung tissue (patient II.1) as described previously $(13,14) .200 \mathrm{ng}$ of genomic DNA was used in the PCR. After denaturation at $95^{\circ} \mathrm{C}$ for $5 \mathrm{~min}, 35$ cycles of denaturation at $95^{\circ} \mathrm{C}$ for $30 \mathrm{~s}$, annealing at $59^{\circ} \mathrm{C}$ for $30 \mathrm{~s}$, and extension at $72^{\circ} \mathrm{C}$ for $45 \mathrm{~s}$ were performed using a thermal cycler (National Labnet Co., Woodbridge, NJ) followed by a 10 -min incubation at $72^{\circ} \mathrm{C}$. The primers used were 5'-GGC CTT GTG TCC AGG GAC-3' in the sense orientation and 5'-TGT GTG TGA GAG TGA GGG TGT AAG- $3^{\prime}$ in the antisense orientation (15), corresponding to positions 1383-1400 and 2135-2158, respectively, of the SP-B gene sequence (7), which are predicted to amplify a 776-bp DNA fragment. After amplification, a 16- $\mu$ l aliquot of the PCR reaction was digested with 15 U of SfuI (Boehringer Mannheim Corp., Indianapolis, IN) using reagents and conditions supplied by the manufacturer. The resulting products were separated on a $2.0 \%$ agarose gel and visualized by ethidium bromide staining.

\section{Results}

SP-B cDNA was detectable by RT-PCR in the lung tissue of the index patient with SP-B deficiency and alveolar proteinosis, although the amount of SP-B-deficient cDNA was markedly less than that generated by RT-PCR from RNA obtained from control lung tissue (not shown). Sequence analysis of the SPB-deficient cDNA clones revealed a substitution of three bases (GAA) for the single nucleotide (C) at position 375 of the SP-B cDNA, disrupting codon 121 (Fig. 1) (referred to as 121ins2). This sequence was found in all cDNAs generated from each set of primer pairs that spanned this region. Direct sequence analysis of genomic DNA from this infant and an affected sibling (patient II.6) confirmed this sequence. The net gain of two bases causes a frameshift, introducing a premature signal for termination of translation after codon 214.

Analysis of SP-B-deficient cDNA clones from both the index patient and an affected sibling (patient II.6) for the sequence distal to the 121 ins 2 mutation indicated the presence of two transcripts, present in approximately equal amounts as determined from multiple PCR reactions. In one of these transcripts exon 7 was deleted, and in a second transcript exon 7 was present, but a cryptic splice site 12 bp $3^{\prime}$ of the reported exon 8 splice junction was used (Fig. 2). The SP-B cDNA did not differ otherwise from the published SP-B DNA sequences, except for a previously unreported single base substitution in

A NORMAL SP-B CDNA

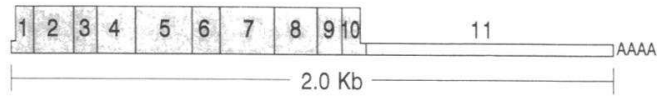

B SP-B DEFICIENT CDNAS

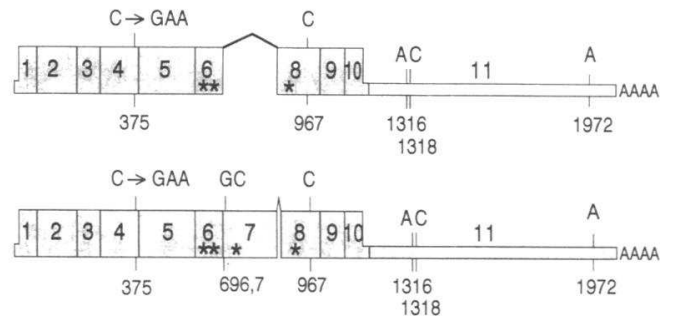

Figure 2. Aberrant splicing of SP-B-deficient transcripts. The normal SP-B mRNA structure is depicted in $A$, with the relative size of each exon indicated. The narrow bars indicate the untranslated regions. The two SP-B-deficient transcripts are depicted in $B$. The position of the 12 lins 2 mutation in exon 4 is shown. At positions where the published cDNA sequences differ (7-10), representing apparent polymorphisms, the nucleotide sequence of the deficient infants is shown. Each transcript was represented by at least two different cDNA clones generated by RT-PCR from patients II.5 or II.6. *Premature termination codon. These sequence data are available from GenBank under accession numbers M24461, M16764, J02761, and M19097.

the 3 ' untranslated region and reported variants at positions $696,697,967,1318$, and $1972(7-10)$.

The 12 lins 2 mutation introduces new restriction sites for SfuI ( TT/CGAA) and TaqI (T/CGA). To determine whether affected infants carried this mutation on both alleles, a 776-bp DNA fragment spanning the restriction site was amplified from genomic DNA from each of the three infants with SP-B deficiency in this family. Treatment of the amplified products with SfuI completely digested the 776-bp fragment to 611 and $165 \mathrm{bp}$ in each of the affected infants, indicating that they were homozygous for this mutation. SfuI digestion of PCR-amplified genomic DNA from both parents indicated that both were heterozygous for the 12 ins 2 mutation. Of the three living children, who along with their parents have no symptoms of pulmonary disease, two are heterozygous for the mutation, and one is homozygous for the normal allele (Fig. 3).

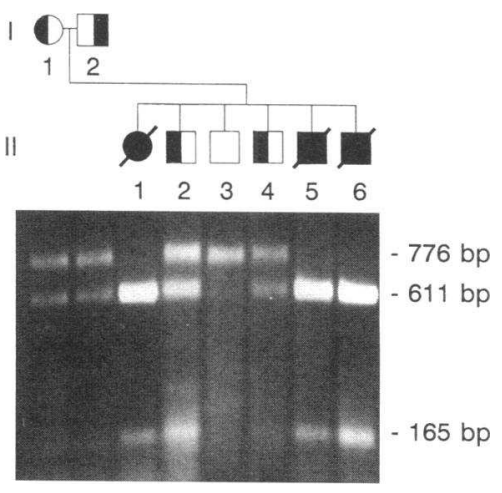

Figure 3. Restriction analysis for the 12 lins 2 mutation in a family with SP-B deficiency. The patterns after SfuI digestion of a 776-bp DNA fragment containing the site of the 12 ins 2 mutation 165 bp from the 5 ' end are shown below the corresponding symbol for each family member. Lines denote bands at 776 (undigested) and

611 and $165 \mathrm{bp}$ (digested). Affected infants (II.1, II.5, and II.6) are homozygous for the restriction site; both parents (I.1 and I.2) and two of their living children (II.2 and II.4) are heterozygous, and a third child (II.3) is homozygous normal. 


\section{CONTROLS}
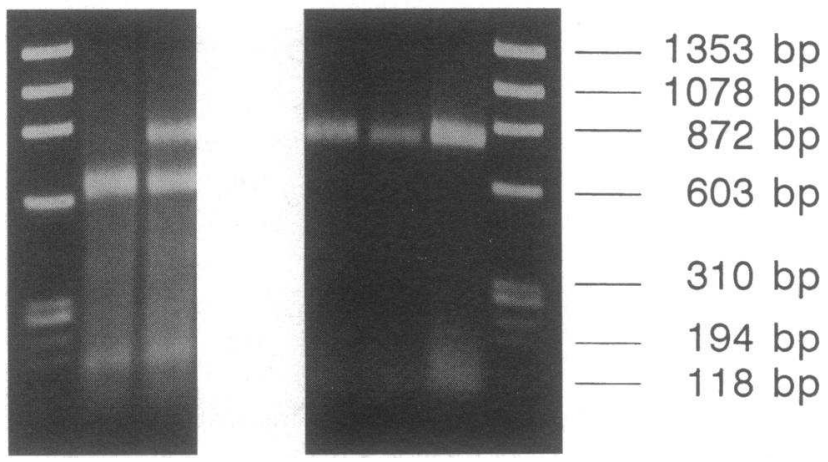

Figure 4. Demonstration of 12 lins 2 mutation in two unrelated infants with SP-B deficiency and alveolar proteinosis. SfuI restriction digests of a 776-bp DNA fragment containing the site of the 12 lins2 mutation $165 \mathrm{bp}$ from the 5 ' end are shown for two infants with alveolar proteinosis and SP-B deficiency (left panel) and for 3 of 50 control patients without lung disease (right panel). The sizes of molecular weight standards (far left and far right) are shown on the right. Patient CAP-2 was homozygous for the restriction site, and patient CAP-3 had this mutation on one allele. DNA from control subjects was not digested.

To ascertain whether the 12 lins 2 mutation was unique to this family, the presence of this mutation was looked for in the DNA of two other unrelated, full-term infants who died from respiratory failure associated with alveolar proteinosis and absent SP-B protein in their lung tissue. Restriction analysis demonstrated that one of these two infants was homozygous for the 121 ins 2 mutation, and the other had the 12 lins 2 mutation on only one allele, suggesting that she was a compound heterozygote for two different SP-B gene defects (Fig. 4). Additionally, the parents of another infant with CAP (5), from whom tissue was not available, were both found to carry this mutation on one allele (not shown), implying that their affected child was homozygous. In contrast, restriction analysis of PCR-amplified genomic DNA obtained from 50 unrelated adult controls without evidence of lung disease did not show the presence of this restriction site on any of the 100 chromosomes analyzed. In 11 of the control patients, two bands of equal intensity were generated by PCR (not shown). This region of the SP-B gene is known to be polymorphic, containing dinucleotide repeats of variable length (15).

\section{Discussion}

CAP is a uniformly fatal lung disease characterized clinically by respiratory failure in the neonatal period and histopathologically by the accumulation of granular, eosinophilic, periodic acid-Schiff reagent-positive staining material in the distal airspaces. The recent observation that three siblings with this disorder lacked SP-B protein suggested that an inherited deficiency of SP-B was the cause of this disease. However, abnormalities of other surfactant components, including increased immunostaining for SP-C, an altered distribution of SP-A staining, and a markedly abnormal amniotic fluid phospholipid profile, were also observed in the SP-B-deficient infants $(2,16)$. Additionally, it was unknown if those observations applied to infants with CAP from other families. In this report, we demonstrate a recurrent mutation in the SP-B gene accounting for the lack of SP-B protein in multiple kindreds, establishing the lack of SP-B as the primary basis for disease in these families and SP-B deficiency as a common cause of CAP. Whether inherited abnormalities of other surfactant proteins produce similar disease is unknown. While the mechanism(s) whereby SP-B deficiency leads to the histopathological appearance of alveolar proteinosis remains unclear, these findings imply a role for SP-B in the metabolism of SP-A, SP-C, and surfactant phospholipids.

The frameshift and consequent premature termination codon clearly account for the lack of the 8,000-D SP-B protein, which is derived from codons 201 to 279 of the 381-amino acid proprotein, and likely account for the marked reduction in SP-B mRNA. The introduction of nonsense codons has been associated with a marked reduction in transcript level from the mutant allele of other genes including $\beta$-globin (17), $\alpha_{1}$-antitrypsin deficiency (18), cystic fibrosis transmembrane regulator (19), fibrillin (20), and the insulin receptor (21). The mechanism(s) leading to reduction in mRNA may be related to alterations in RNA processing (22-24). The mechanisms and significance of the abnormalities in SP-B RNA splicing observed in the index patients (Fig. 2) are unclear. Both alterations are distal to the premature termination codon, which is in exon 6 , and are thus unlikely to be causally related to the deficiency of SP-B protein. Abnormalities of RNA splicing have been observed in mutant alleles of other genes containing premature termination codons $(20,25)$. Alternatively, these splicing abnormalities may also occur in normal tissue and were selected because of the marked reduction in normal SP-B transcript levels.

The incidence of SP-B deficiency associated with alveolar proteinosis is unknown. Affected infants also have features of respiratory distress syndrome, persistent pulmonary hypertension, and bronchopulmonary dysplasia and may not be recognized without autopsy or biopsy data or until a second child in the same family is affected $(2,6)$. It is therefore likely that the syndrome has been underreported. Finding the identical mutation on seven of eight chromosomes from unrelated infants raises the possibility that the disease may be more common than has been appreciated and indicates that molecular techniques will be useful in diagnostic testing. Whether the presence of the same mutation in unrelated individuals is because of a mutation arising in a common ancestor or reflects a mechanism causing a recurrent de novo mutation at this site is unknown. The finding of an apparent compound heterozygote SP-B-deficient patient suggests there is some molecular heterogeneity of this disorder.

At the present time there is no effective treatment for neonatal alveolar proteinosis, and gene therapy may be required to treat this disorder. Gene therapy trials for SP-B deficiency, which has a rapidly progressive course, may be helpful in developing strategies for treatment of other genetic illnesses such as cystic fibrosis and $\alpha_{1}$-antitrypsin deficiency which lead to more gradually progressive pulmonary disease.

\section{Acknowledgments}

We thank Drs. Joel Haas, T. Allen Merritt, Henri Krous, and Paul Dykema for providing patient specimens; Dr. Garry R. Cutting for 
providing control DNA specimens; and Larry Jones, Ling Peng, and Ray Kendzior, Jr. for technical assistance.

This work was supported in part by grants from the National Institutes of Health (HL-37591 to H. R. Colten, HL-34748 to D. E. deMello, HL-50184 to A. M. Murphy, and HL-02815 to H. C. Dietz). L. M. Nogee is the recipient of a Basil O'Connor Scholar Award from the March of Dimes, and A. M. Murphy is the recipient of a Clinician Scientist Award from the American Heart Association.

\section{References}

1. Farrell, P. M., and M. A. Avery. 1975. Hyaline membrane disease. Am. Rev. Respir. Dis. 111:657-688.

2. Nogee, L. M., D. E. deMello, L. P. Dehner, and H. R. Colten. 1993. Deficiency of pulmonary surfactant protein B in congenital alveolar proteinosis. $N$. Engl. J. Med. 328:406-410.

3. Coleman, M., L. P. Dehner, R. K. Sibley, B. A. Burke, P. R. L'Heureux, and T. R. Thompson. 1980. Pulmonary alveolar proteinosis: an uncommon cause of chronic neonatal respiratory failure. Am. Rev. Respir. Dis. 121:583-586.

4. Knight, D. P., and J. A. Knight. 1985. Pulmonary alveolar proteinosis in the newborn. Arch. Pathol. Lab. Med. 109:529-531.

5. Schumacher, R. E., A. J. Marrogi, and K. P. Heidelberger. 1989. Pulmonary alveolar proteinosis in a newborn. Pediatric Pulmonology. 7:178-182.

6. Moulton, S. L., H. F. Krous, T. A. Merritt, R. M. Odell, E. Gangitano, and J. D. Cornish. 1992. Congenital alveolar proteinosis: failure of treatment with extracorporeal life support. J. Pediatr. 120:297-302.

7. Pilot-Matias, T. J., S. E. Kister, J. L. Fox, K. Kropp, S. W. Glasser, and J. A. Whitsett. 1989. Structure and organization of the gene encoding human pulmonary surfactant proteolipid SP-B. DNA $(N Y)$. 8:75-86.

8. Glasser, S. W., T. R. Korfhagen, T. Weaver, T. Pilot-Matias, J. L. Fox, and J. A. Whitsett. 1987. cDNA and deduced amino acid sequence of human pulmonary surfactant-associated proteolipid SPL(Phe). Proc. Natl. Acad. Sci. USA. 84:4007-4011.

9. Jacobs, K. A., D. S. Phelps, R. Steinbrink, J. Fisch, R. Kriz, L. Mitsock, J. P. Doughterty, H. W. Taeusch, and J. Floros. 1987. Isolation of a cDNA clone encoding a high molecular weight precursor to a 6-kda pulmonary surfactant-associated protein. J. Biol. Chem. 262:9808-9811.

10. Revak, S. D., T. A. Merritt, E. Degryse, L. Stefani, M. Courtney, M Hallman, and C. G. Cochrane. 1988. Use of human surfactant low molecular weight apoproteins in the reconstitution of surfactant biologic activity. J. Clin. Invest. 81:826-833.

11. Chomczynski, P., and N. Sacchi. 1987. Single-step method of RNA isolation by acid guanidinium thiocyanate-phenol-chloroform extraction. Anal. Biochem. 162:156-159.
12. Sanger, F., S. Nicklen, and A. R. Coulson. 1977. DNA sequencing with chain-terminating inhibitors. Proc. Natl. Acad. Sci. USA. 74:5463-5467.

13. Sambrook, J., E. F. Fritsch, and T. Maniatis. 1989. Molecular Cloning: A Laboratory Manual. Cold Spring Harbor Laboratory, Cold Spring Harbor, NY. 9.17-9.19.

14. Rogers, B. B., L. C. Alpert, E. A. S. Hine, and G. J. Buffone. 1990. Analysis of DNA in fresh and frozen tissue by the polymerase chain reaction. Am. J. Pathol. 136:541-548.

15. Todd, S., and S. L. Naylor. 1991. Dinucleotide repeat polymorphism in the human surfactant-associated protein 3 gene (SFTP3). Nucleic Acids Res. 19:3756.

16. Nogee, L., W. Hull, J. Whitsett, A. Hamvas, and F. S. Cole. 1993. Inherited surfactant protein B deficiency: prenatal diagnosis. Pediatr. Res. 33:227a. (Abstr.)

17. Baserga, S., and E. J. Benz, Jr. 1988. Nonsense mutations in the human $\beta$-globin gene affect mRNA metabolism. Proc. Natl. Acad. Sci. USA. 85:20562060.

18. Satoh, K., T. Nukiwa, M. Brantly, R. I. Garver, Jr., M. Hof ker, M. Courtney, and R. G. Crystal. 1988. Emphysema associated with complete absence of $\alpha 1$-antitrypsin of a stop codon in an $\alpha 1$-antitrypsin-coding exon. Am.J. Hum. Genet. 42:77-83.

19. Hamosh, A., B. C. Trapnell, P. L. Zeitlen, C. Montrose-Rafizadeh, B. J. Rosenstein, R. G. Crystal, and G. R. Cutting. 1991. Severe deficiency of cystic fibrosis transmembrane conductance regulator messenger RNA carrying nonsense mutations R553X and W1316X in respiratory epithelial cells of patients with cystic fibrosis. J. Clin. Invest. 88:1880-1885.

20. Dietz, H. C., D. Valle, C. A. Francomano, R. J. Kendzior, Jr., R. E. Pyeritz, and G. R. Cutting. 1993. The skipping of constitutive exons in vivo induced by nonsense mutations. Science (Wash. DC). 259:680-683.

21. Kadowaki, T., H. Kadowaki, M. M. Rechler, M. Serrano-Rios, J. Roth, P. Gorden, and S. I. Taylor. 1990. Five mutant alleles of the insulin receptor gene in patients with genetic forms of insulin resistance. J. Clin. Invest. 86:254-264.

22. Urlaub, G., P. J. Mitchell, C. J. Ciudad, and L. A. Chasin. 1989. Nonsense mutations in the dihydrofolate reductase gene affect RNA processing. Mol. Cell. Biol. 9:2868-2880.

23. Belgrader, P., J. Cheng, and L. E. Maquat. 1993. Evidence to implicate translation by ribosomes in the mechanism by which nonsense codons reduce the nuclear level of human triosephosphate isomerase mRNA. Proc. Natl. Acad. Sci. USA. 90:482-486.

24. Cheng, J., and L. E. Maquat. 1993. Nonsense codons can reduce the abundance of nuclear mRNA without affecting the abundance of pre-mRNA or the half-life of cytoplasmic mRNA. Mol. Cell. Biol. 13:1892-1902.

25. Fisher, C. W., C. R. Fisher, J. L. Chuang, K. S. Lau, D. T. Chuang, and R. P. Cox. 1993. Occurrence of a 2-bp (AT) deletion allele and a nonsense (G-toT) mutant allele at the E2 (DBT) locus of six patients with maple syrup urine disease: multiple-exon skipping as a secondary effect of the mutations. $A m$. $J$. Hum. Genet. 52:414-424. 